HONG KONG AND AUSTRALIAN SENIORS: VIEWS OF AGING AND LEARNING

G. Boulton-Lewis ${ }^{1}$, M. Tam ${ }^{2}$, L. Buys ${ }^{3}$, E. Chui ${ }^{4}, 1$. Queensland University of Technology, Brisbane, Queensland, Australia, 2. The Education University of Hong Kong, Hong Kong, Hong Kong, 3. School of Design, QUT, Queensland, Queensland, Australia, 4. The University of Hong Kong, Hong Kong, Hong Kong

Qualitative, semi-structured interviews, using open ended questions, were conducted with 40 older Australians and 39 seniors in Hong Kong who either had or had not engaged in organized learning in the last six months.

The samples were chosen using a purposive sampling strategy. In Australia participants were identified from 400 respondents to a Perceptions of Learning Survey distributed through seniors' organisations. In Hong Kong the respondents participated in the same survey and were invited to take part in follow up interviews.

Interviews were recorded, translated in Hong Kong, and transcribed,

Phenomenology was used to guide the interviews and analysis to explore the experiences and perspectives of these older people.

The biggest difference in views of aging was that $20 \%$ of the Hong Kong group as compared with 5\% in Australia talked about aging in terms of decline. The views of learning also differed in both places. In Hong Kong 25\% the main focus of learning was about health as compared with $5 \%$ of Australians.

The results and differences will be discussed in terms of life history in interaction with environment and values of culture and community. The implications will also be considered.

\section{LEARNING FOR AND BY SENIOR ADULTS: AN ASIAN PERSPECTIVE}

M. Tam, The Education University of Hong Kong, Tai Po, Hong Kong

Each culture has beliefs and ideas about the lifecycle including how people age and learning in later life. This presentation discusses the influence culture has on the view of ageing and older adults learning. It also attempts to elucidate what ageing and learning mean to people across different cultures.

With respect to learning, there is no shortage of research into the relationship between culture and learning. Yet much of it is confined to comparisons between Eastern and Western cultures. However, the East-West view of culture and learning has been criticized for being overly simplistic because cultures may overlap to result in both similarities and differences as people conceptualize and experience learning in different cultural contexts. With a focus on the Asian perspective, or more specifically, the Confucian philosophy of lifelong learning, this presentation discusses the cultural meaning of lifelong learning for older people in their cultural and social contexts.

\section{SESSION 5085 (SYMPOSIUM)}

\author{
RAISING AWARENESS ABOUT HEALTH EQUITY, \\ PRODUCTIVE AGING, AND AT-RISK OLDER ADULTS \\ Chair: E. Gonzales, Boston University, Boston, \\ Massachusetts
}

Co-Chair: R. Harootyan, Senior Service America Inc, Silver Spring, Maryland

Discussant: C. Matz-Costa, Boston College

This symposium integrates the phenomena of health equity and productive aging to help identify solutions that address disparities in health. We define health equity as social justice in health; measures of health disparities indicate the degree of inequity. Productive aging is defined as any activity that produces a good or services for society, whether paid for or not (e.g., employment, caregiving). How can social structures be revamped or expanded to promote greater productivity and health equity? How can policies and programs maximize positive outcomes for individuals and society?

Harootyan underscores the challenges in promoting computer literacy among offline older adults and presents multivariate survey results indicating how special computer training approaches not only improve older adults' instrumental skills but their mental health as well. Yulikova presents data on how a state's programs for disadvantaged unemployed seniors integrate many approaches to achieve productive engagement while also promoting self-health awareness/management. Lee et al. offer evidence that reducing financial hardship among racial minority family caregivers can improve the caregiver's health, regardless of differences in the care recipient's level of functional limitations. Gonzales et al. identify how cumulative inequality or unanticipated shocks disrupt the aging process and place unemployed older adults in tenuous circumstances leading to enrollment in SCSEP; yet, participants also reported resilience with high levels of individual, institutional, and environmental resources that promote their health.

Altogether, these quantitative and qualitative studies raise awareness of health inequities among at-risk older Americans and offer implications for policies and practices that can reduce health disparities.

\section{EXPLORING HETEROGENEITY OF CO-OCCURRING RISKS AND RESOURCES AMONG AT-RISK OLDER ADULTS}

E. Gonzales ${ }^{1,2}$, R. Harootyan ${ }^{3,2}$, K. Lee Le, $^{4,2}$ 1. School of Social Work, Boston University, Boston, Massachusetts, 2. Center for Innovation in Social Work and Health, Boston, Massachusetts, 3. Senior Service America, Inc., Silver Spring, Maryland, 4. Ohio State University, Columbus, Obio

This study explores the heterogeneity of co-occurring risks, barriers, resources, and preferences among at-risk older adults in the Senior Community Service Employment Program (SCSEP).

In-depth individual semi-structured interviews were conducted with 26 participants that explored risks, barriers, resources (individual, institutional, environmental), and workforce preferences. Interviews were audio-recorded and transcribed verbatim. Themes and variations across properties and dimensions were identified using constant comparison technique.

Two major themes emerged: cumulative disadvantages and highly disruptive shocks (health, economic or social) that led to SCSEP participation. While co-occurring risks and barriers were evident, many participants reported improved health during their SCSEP tenure. This study expands our understanding of SCSEP as having aspects of 